\title{
Desire and Violence in Modern Sport
}

\author{
Takuya Sakamoto
}

\author{
Meisei University \\ 2-1-1 Hodokubo, Hino-shi, Tokyo 191-8506, Japan \\ takuya.sakamoto@meisei-u.ac.jp
}

[Received December 19, 2016; Accepted August 25, 2017; Published online September 5, 2017]

\begin{abstract}
Why do we want to win in a sport as strongly as we do? This paper explored this question from the point of view of desire in an attempt to delineate how desire manifests in modern sports, as well as its relevance to brutality. A great many incidents that occur in real life teach us that modern sports involve a great deal of violence. It is equally clear that no violent behaviour will happen in a situation where no competition exists. As we confirmed at the outset, competitors are bound to have an essential desire to win in sports competitions. This desire is directed towards an object called victory. According to Girard, the desire to win is anything but autonomous; rather, it exists as the mimicry of another person's desire. When revisiting modern sports from the point of view of desire in this manner, we can see that international megaevents such as the Olympics, the world cups of various sports, etc., propagate our desire to win to a formidable degree. In other words, modern sports are intimately connected with capitalist economies and strengthen triangular desire in a synergistic manner. The strengthened desire lacks an outlet, reaches the hell of reciprocal mediation, and consequently manifests as brutality.
\end{abstract}

Keywords: René Girard, triangular desire, winning, scuffle, nationalism

\section{Introduction: viciousness in modern sports}

A great many incidents that occur in real competitive sporting life teach us that modern sports involve a great deal of violence*1. For example, an Internet site, MUNDO DEPORTIVO (2016), published a story entitled 'Tragedy in Mexico: Player Outraged by Red Card Retaliates. Chief Referee Head-Butted and Killed.' From a common-sense standpoint, it is difficult for observers to understand why a player would be so outraged that he used violence to kill the chief referee after being sent off in a football match. In fact, this incident took place during an amateur league game and no prize money was at stake. The general impression might, therefore, be that there was no need to become so worked up about the match. Although such homicides are extremely rare, violence committed by players-such as scuffles during matches-is an increasingly common phenomenon seen across the globe, and it is not unusual to see football fans stimulated by a game going on a rampage, not to mention the players themselves.

Of course, there are discrete reasons and backgrounds behind each such occurrence. Nevertheless, it can be assumed that a common factor underlies modern sports. As Elias and Dunning (1986) once pointed out, it is safe to say that our society has advanced to the point that we discourage observable violence. They also saw this 'civilizing process' in the historical transitions of sports culture. However, this discussion was tantamount to a relativisation of sports as well as the violence associated therewith based on the axis of history, and the problem we must now address is the brutality of sports occurring now, before of our eyes. In other words, even if it is true that sports have become less brutal over time, an element of that violence still persists today, and it is not something to be discussed in relative terms: It is a pressing problem.

This awareness is the defining difference between this paper and a number of historical sociological literatures which have been published actively. In fact, those traditional literatures have tried to inquire the social factors of the sports violence or to illuminate the features of our society through the violence phenomenon in the competitive sporting world. As a typical example of the former, Lewis noted that 'the violence affects and can be affected by many segments of society: the scholarly community, the mass media, the athletes, the police, and violent fans themselves' (2007, p.139). Similarly, as the latter which has been characterized by Elias, Taki expressed the methodological attention as the 
term 'sports as a method of questioning' (1995, p.7) and he suggested that 'to inquire sports is equally to inquire society' $(1995, \mathrm{p} .23)$. The historical sociological studies thus have not lead to an answer to the problem suggested above, although those studies are effective for understanding our society.

Therefore, the philosophy of sports must question in a pure form why it persists. This paper explores this question from the point of view of desire in an attempt to delineate how desire manifests in modern sports, as well as its relevance to brutality. To this end, this paper would clarify the existence of the desire and violence in sports, through taking football as mentioned above. It is the fact that the most of past discussions about sports violence took football as examples for their discussions. This fact suggests that football is most suitable theme for showing clearly the relationship between violence and desire in sports. As I discuss below, however, this paper ultimately intends to reveal a distinguishing characteristic of the desire which is contained in modern sport, by using football as key examples*2.

\section{Why do we want to win?}

In the first place, why do we want to win in a sport as strongly as we do? This is a simple and thus a fundamental question. According to sports ethics, aiming for victory is the most fundamental condition for sports competitions. In other words, it is absolutely not permitted for competitors not to aim for victory in their sports competitions, or, more specifically, in each of their games. This is clear from the following example: A basketball game would not qualify as such if all players sat down on the court as soon as a jump ball was tossed up to begin the game. For a sport competition to qualify as such, participants must, at a minimum, aim for victory within the scope of the rules, and it is in this sense that aiming for victory constitutes an essential condition for sport competitions.

However, this is a discussion of the essence of sports competitions themselves, not necessarily a discussion of competitors. Nevertheless, to answer the question of why competitors want to win, it is necessary to focus on them. This is because it is competitors themselves who want to win, and this desire for victory is closely connected with the brutality of sports*3.

As mentioned above, competitors are required to aim for victory in each of their games. If they lose their desire to win, there can be no competition, a fact that simultaneously implies the following: When brutality emerges in a sport, the condition for wanting to win has already been met, because competition cannot arise if competitors do not want to win. It is equally clear that no violent behaviour will happen in a situation where no competition exists. Hence, sport competitions essentially involve brutality. This is also clear from the fact that brutality can take various forms, regardless of place and time. Furthermore, Elias's discussion of the civilizing process, mentioned above, implies this fact. Although brutality is an essential aspect of sports, the prohibition of violence has been historically appealed to and brought forward as a matter of fact.

This makes clear the connection between the desire for victory and brutality, but the following question remains. Why do we want to win as much as we do? To put it somewhat differently, why do we have a desire to win? It is here that the theory of desire in sports finds its place. I would now like to interpret brutality in modern sports using Girard's theory of desire, which brilliantly delineates the nature of desire in competitive relationships. As far as I know, there has been no study that has considered the brutality of sports from the perspective of theory of desire. Therefore, my argument will reveal a new understanding of the nature of desire as manifested in modern sports, as well as its relevance to brutality.

\section{Girard's theory of triangular desire}

René Girard can be characterised primarily as an anthropologist who was born in France and worked mainly in universities in the United States. I say 'primarily' because his overall research went beyond the single academic field of cultural anthropology, and his discussions often encompassed a wide range of academic fields, including philosophy, sociology, history, and religious studies. In any case, Girard's theory of desire is based on the plurality of looks that human beings can express.

In some of the academic fields, the features of Girard's theory of desire have been described. Tominaga (2014, p.381), for example, emphasised Girard's originality that he separates the mediation forms of desire into two manners, i.e., external and 
internal as I mention below, and then it could be possible to depict complex human emotions which had never been discussed by the past sociological theory of desire. Although Matsutani (2007, p.281) criticised that it is difficult to describe the modern political power and violence by Girard's theory of desire, he also values Girard's radical critique of culture and points out that Girard's theory could illuminate the nature of human desire. Furthermore, as literatures focusing on modern education system by the point of view of Girard's desire theory, Kameyama (2001) delineates the existence of violence in school and classroom, and Kano (2014) also explains the generating mechanism of bullying and corporal punishment in detail.

Girard's theory of desire, as remarked above, have been applied in various fields, the social theory, political theory, and educational theory and so on. This is nothing less than an indication of the applied possibility of Girard's theory, as Gebauer and Wulf notes 'Girard maintains of mimetic mediation that it is a general principle of society' (1995, p.235). This paper also adopts this methodological perspective and applies it to quest for the violence in modern sports. Here, in order to elucidate the characteristics of Girard's theory of desire, I would like to show its main thrust. He asserted that human desire must be understood as one person mimicking the desires of another. He called this 'triangular desire' (1966), and presented it as a concept slightly different in meaning from what we commonly understand by the term 'desire'. Desire is certainly to want something, but Girard distinguished it from biological desires such as the appetite for food, sexual desire, etc. What Girard particularly emphasised was not the objects of such wants and appetites, but the nature of desire itself.

In general, when we think of a desire, we automatically assume that said desire takes the form of a subject wanting an object. For instance, when I say 'I would like to have a new golf club', 'I' is the subject of desire, while 'golf club' is the object of desire. Girard described the nature of such desire as a 'straight line' (1966, p.2), and suggested with irony that 'it can always be portrayed by a simple straight line which joins subject and object.' (1966, p.2) He further criticised such linear desires as nothing more than a naive 'illusion' (1966, p.16) on our part. If, however, the nature of (linear) desire that we ordinarily assume is an illusion, what is the proper way of understanding the concept of desire?

Girard described this problem as follows: 'the mediator is there, above that line, radiating toward both the subject and the object.' (1966, p.2) According to him, our desire comprises a tripartite relationship: subject-mediator-object. In other words, we are not aware of mimicking the desires of others, but instead fall under the illusion that our desire is autonomous. I would like to review this point using the previous example. When I say 'I want a new golf club', 'I' myself think that I autonomously want a 'golf club'. In fact, however, this want is nothing more than a mimicry, not of 'my' desire but the desire of another person (a mediator). To put it plainly, in the relationship of young brothers, the younger brother (subject) wants whatever (object) his older brother (mediator) has. In particular, phenomena sometimes observed in a younger brother desiring items such as moderately difficult toys that are thought to be hard for him to play with, symbolizes the triangular nature of desire. In other words, what is important to him is not the content of an object, but rather, the very fact of another person (mediator) desiring or possessing it.

Now, I would like to delineate the brutality of modern sports while deepening the discussion on Girard's argument from the viewpoint of triangular desire. Behind Girard's stringent criticism of the autonomy of the subject that desires is the fact that he sought to build an argument against Freud's thendominant theory of self. Furthermore, some recent attempts have been made to question how sports club activities and sports groups should exist, based on Girard's discussion. Sakamoto (2012), for instance, pointed out that the unaware competition among sports coaches could be excessive in school athletic club activities, and Matsuda (2016) described the emergence of violence in sports groups. These discussions are entirely preoccupied with the attention to the violence or competition 'inside' sports groups or school athletic clubs. Therefore, they did not focus on the underlying desire in a broad context of modern sports, and rather this paper would show just the existence of broader universal desire. 


\section{A consideration of modern sports in light of the theory of desire}

As we confirmed at the outset, competitors are bound to have an essential desire to win in sports competitions. This desire is directed towards an object called victory. According to Girard, the desire to win is anything but autonomous; rather, it exists as the mimicry of another person's desire. How, then, are the nature of desire and the brutality of modern sports related?

Girard argued that if the 'spiritual' (1966, p.9) distance between a subject and its mediator is close, these two constitute a 'rival' (1966, p.7). For example, the spiritual distance between competitors who demonstrate similar performances is close, whereas two competitors with disparate abilities-say, me and Usain Bolt-is infinitely distant. Girard did not argue that the physical distance between the subject and the mediator does not affect their relationship; however, he asserted that spiritual distance clearly affects it more strongly. In other words, when the spiritual distance is short, we call it a rivalry relationship, and when it is long, a relationship of esteem or yearning is formed. Girard called the nature of desire when close 'internal mediation', and when distant 'external mediation' $(1966$, p.9).

Girard suggested that an internally mediated rivalry relationship creates a more serious human relationship, as its spiritual distance is shorter. This is because the mediator, like the subject, may mimic the desire of the subject. Girard called the power of perpetuating triangular desire in this manner 'metaphysical virtue' (1966, p.84): 'as the mediator draws nearer, passion becomes more intense and the object is emptied of its concrete value.' (1966, p.85) The object of desire in a sports competition is nothing other than victory. Therefore, according to Girard, as the rivalry relationship gets stronger, the object of desire, i.e., victory rather loses its original value. This explains the brutality inherent in sports competitions-but what does that mean?

Scuffles-a typical example of the brutality in sports manifesting-occur if two (or more) opponents are in close proximity, i.e., a mediator of desire is very close both physically and spiritually. This can be understood as an action that results from victory; an object of desire can be overwhelmed by hostility towards an opponent that is triggered by a certain play, following a complex enhan- cement of the rivalry as a result of multiple effects (metaphysical efficacy), whereas the subject was originally supposed to desire an object called victory. In other words, the object of desire, victory, became the 'only a means' $(1966$, p.53) of defeating the rival: 'The desire is aimed at the mediator's being.' (1966, p.53) It should be noted that this shift is not necessarily recognized by competitors themselves (the subjects of desire). That is, the relevant persons may not understand why they get into scuffles, because 'there is a sterile opposition of contraries, which becomes more and more atrocious and empty as the two subjects approach each other and as their desire intensifies.' (1966, p.100) Girard described this state as 'the hell of reciprocal mediation' (1966, p.104), and represented it as the extremity of brutality in triangular desire.

We now have a subject-mediator and a mediatorsubject, a model-disciple and a disciple-model. Each imitates the other while claiming that his own desire is prior and previous. Each looks on the other as an atrociously cruel persecutor. (1966, p.99)

This applies to modern sports in an even broader context. As Girard suggested in his comment that 'metaphysical desire is always contagious' (1966, p.99), triangular desire is not solely a problem between rival competitors. As I mentioned previously, such desires are transmitted and expanded to fans who become excited while watching from the stands, as well as to viewers watching the match via television or other devices. I will use Japan-Korea football matches as a specific example of this to further advance the discussion.

In Japan-Korea football matches, Japan's mass media add fuel to competitiveness beyond necessity, and call the opponent a permanent rival. This attitude induces a contagion of triangular desire, thus demonstrating its metaphysical efficacy. In a game that was originally played by 22 players, the desire to win spreads to the entire stadium and, on some occasions, to an even larger audience. It may seem natural for fans to desire their team to win; thinking of it logically, however, the reason that the sense of rivalry grows in the stands even if fans themselves do not compete in any way is not necessarily selfevident. Here, we can see the dual character of desire: Although fans mimic their national players' desire to win, they fail to recognize this, and think of it as if it is they themselves who could win the 
match. Because this occurs on both sides, fans find themselves building a rivalry. This fact can also be understood as the short physical and spiritual distances between Japan and Korea, including their complex history. The so-called problem of nationalism is thus not simply a political problem: At the root of it lies our mimetic desire, which drives us to perpetual competition. The nature of such desire is that 'the more intense the hatred the nearer it brings us to the loathed rival' (Girard, 1966, p.100). Stories such as this are not confined to Japan and Korea, or to football; the same is true at the nation$\mathrm{al}$ and the domestic team levels. This should be clear from the fact that there are innumerable "derby matches" around the globe.

When revisiting modern sports from the point of view of desire in this manner, we can see that international mega-events such as the Olympics, the world cups of various sports, etc., propagate our desire to win to a formidable degree. Not only the actual competitors but also the audiences and viewers contribute to strengthening the metaphysical efficacy of triangular desire. The problem is that this exists as a metaphysical force, and of course it is a force that cannot be seen with our eyes or recognized by the relevant people.

Furthermore, it should be pointed out that such international competitions are relatively rare, as they are held only once every four years, which simultaneously enhances their economic value. As Saeki pointed out, in today's capitalist economy, our 'object of desire tends to centre on a single point' (1993, p.89). Rarity strengthens the desire to win that abounds in modern sports facilities in various ways. In other words, modern sports are intimately connected with capitalist economies and strengthen triangular desire in a synergistic manner. The strengthened desire lacks an outlet, reaches the hell of reciprocal mediation, and consequently manifests as brutality.

\section{Conclusion}

In sports, Girard answered the question of why we want to win as much as we do in the following manner: Because others want to win. Triangular desire increases in meetings of people who share an uncritical desire to win, including competitors, teams, staff, and fans. This seems natural to us. If, however, there is no opponent or rival to compete with, eagerness for victory, enthusiasm for the game, and violence as transgression will not all manifest. Of course, not all triangular desires lead to violence. What is revealed in this paper is rather the essential nature of the desire of competitors, which can take the seemingly contradictory forms of both athletic prominence and violent behaviour. As I mentioned in the introduction, the desire to win is essential for a sports competition to qualify as such. We should thus recognize that the desire itself existed prior to its manifestation in various forms, in both positive and negative behaviour at sports facilities. The existence of desire, described with Girard's theory in this paper, is a kind of universality. We are then obliged to confront the sport in question while recognizing this ambiguous possibility. This understanding of the ambiguous desire might be also connected to the discussion of sport integrity. For instance, it could be considered in light of the ambiguous desire that there are differences between athletes who want doping and others who do not want it, or between some sporting people that engage in organized cheating and others that do not engage in it, because the desire, as shown above, affects not only competitors but also staff and so on. Hence, this paper presented a basic framework of the theory of competitor's desire, and it could be an effective viewpoint for inquiring this sport integrity which is discussed in various levels. In our present discussion, the first step would be to look directly at the character of desire as exhibited in modern sports and to recognize it.

\section{Notes}

*1: In this paper, the term 'modern sports' is defined and confined as 'the competitive sports activities carried out under written rules' in the broadest sense, because it seems that the activities for recreation or just fan do not relate to the desire for victory. Those activities thus are not coverage of this paper. Although this definition is expedient, it would be adequate for the discussion of inquiring a kind of universal desire in the competitive sporting world.

*2: Of course, as Todd (2011) expressed, the violence or aggression could appear not only in football but also in both individual sports and team sports. Nevertheless, the contextual culture of those sports also influence the appearance of violence in modern sports. For example, it might not have been seen that the scuffle happens in swimming competition despite the existence of the intense competition among athletes. Therefore it seems that swimming is further away from the violence as compared to football. This kind of difference relevant to the contextual culture of each sports should be considered with a lot of examples from various perspectives. However, this paper would rather function 
more like a preliminary consideration of the studies referred to the cultural difference. In other words, to offer a tentative proposal about the relationship between desire and violence in competitive situation. More correctly, as I discuss below, this paper intends to clarify the existence of a universal desire in modern sports which lies at the root of the contextual difference. Hence it could be described that the contextual difference could be an influential factor and a significant contention in the step that after only the universal desire emerges.

*3: In regard to this point, this paper stands at variance with the previous literatures of sports philosophy. Kretchmar (2014), for instance, in his recent work 'A Phenomenology of Competition', described the central features of competition employing Husserl's phenomenology. However, this approach also did not provide any understanding of the competitor's desire for victory.

\section{References}

Elias, N. and Dunning, E. (1986). Quest for Excitement: Sport and Leisure in the Civilizing Process. Amsterdam: University College Dublin Press.

Gebauer, G. and Wulf, C. (1995). Mimesis: Culture-Art-Society (Reneau, D. Trans.). University of California Press. (Original work "Mimesis: Kultur, Kunst, Gesellschaft" published 1992)

Girard, R. (1966). Deceit, Desire and the Novel: Self and Other in Literary Structure (Freccero, Y. Trans.). London: Johns Hopkins University Press. (Original work "Mensonge romantique et vérité romanesque" published 1961)

Kameyama, Y. (2001). Kodomo to aku no ningengaku: Kodomo no saihakken no tameni [Anthropology of Child and Evil: For rediscovering child]. Tokyo: Ibunsha. (in Japanese)

Kano, Y. (2014). Modern School Education System and Violence: with a focus on "corporal punishment" and “bullying”, Jpn. J. Sport Sociol., 22: 7-20. (in Japanese)

Kawatani, S. (2005). Lectures of Sport Ethics. Kyoto: Nakanishiya Press. (in Japanese)

Kretchmar, S. (2014). A Phenomenology of Competition. J. Philos. Sport, 41: 21-37.

Lewis, J. M. (2007). Sports Fan Violence in North America. Maryland: Roman \& Littlefield Publishers.

Matsuda, T. (2016). The violent in relations among players in sports groups: focusing on Girard's theory on violence. J. Philos. Sport Phys. Educ., 38: 23-36. (in Japanese)

Matsutani, K. (2007). Girard's Theory of Violence and the Logic of Politics. J. Social Sci., 60 COE Special Edition: 267-286. (in Japanese)

MUNDO DEPORTIVO (2016). Mata a un árbitro y sale huyendo en México. http://www.mundodeportivo.com/ vaya-mundo/20161107/411647907136/arbitro-asesinadomexico-amateur.html. (accessed 2016-12-16).

Saeki, K. (1993). "Desire" and Capitalism: Logic of endless expansion. Tokyo: Kodansha. (in Japanese)

Sakamoto, T. (2012). Structural analysis of school athletic club: on the human body as a basis. J. Philos. Phys. Educ.,
42: 51-54. (in Japanese)

Taki, K. (1995). Supotsu wo kangaeru: shintai, shihon, nationalism [Thinking Sports: body, capital, nationalism]. Tokyo: Chikumashobou. (in Japanese)

Todd, J. R. (eds.), (2011). Violence and Aggression in Sporting Contests: Economics, History and Policy. New York: Springer.

Tominaga, S. (2014). Girard, R. "Mensonge romantique et vérité romanesque" (1961). In Mita, M et al. (eds.), Encyclopedia of Basic Books in Sociology (p.381). Tokyo: Kobundo. (in Japanese)

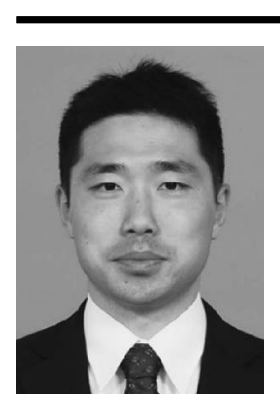

Name:

Takuya Sakamoto

Affiliation:

School of Education, Meisei University

\section{Address:}

2-1-1 Hodokubo, Hino-shi, Tokyo 191-8506, Japan

Brief Biographical History:

Dr. Takuya Sakamoto is the Associate Professor at Meisei University (2017-) and he has a strong interest in the desire in sport. Especially, he is developing the study of anti-doping (education) from the viewpoint of the phenomenological ethics, which includes Merleau-Ponty's thought. Additionally, he also advances the study of the lived body of physical education teacher or sports coach from the existential perspective.

\section{Main Works:}

-Sakamoto, T. (2017) Desire in the issue of doping: for the development of anti-doping education in Japan. J. Philos. Sport Phys. Educ. (in press). (in Japanese)

-Sakamoto, T. (2015) Formation process of body culture as "PE teacher identity": An introduction to the PE teacher body theory. Int. J. Sport Health Sci. 13: 23-34.

-Sakamoto, T. (2012) A critical consideration of the argument on PE teacher: For body theory of PE teacher. J. Philos. Sport Phys. Educ. 34(1): 23-36. (in Japanese)

-Sakamoto, T. (2011) Body in school athletic Club: Focusing on handing down of corporal punishment. J. Philos. Sport Phys. Educ. 33(2): 63-73. (in Japanese)

Membership in Learned Societies:

-Japan Society of Physical Education, Health and Sport Sciences

-Japan Society for the Philosophy of Sport and Physical Education

- Japanese Society of Sport Education

-The International Association for the Philosophy of Sport

-Philosophy of Education Society of Great Britain 